\title{
Bio-inspired Surfactant Assisted Nano-Catalyst Impregnation of Solid-Oxide Fuel Cell (SOFC) Electrodes
}

Ozcan Ozmen ${ }^{\mathrm{a}, \mathrm{b}}$, John W Zondlo ${ }^{\mathrm{c}}$, Shiwoo Lee ${ }^{\mathrm{b}, \mathrm{d}}$, Kirk Gerdes ${ }^{\mathrm{b}}$, Edward M. Sabolsky ${ }^{\mathrm{a}, \mathrm{b}, *}$

${ }^{a}$ Department of Mechanical \& Aerospace Engineering, West Virginia University, Morgantown, WV 26506, USA

${ }^{\mathrm{b}}$ US DOE-National Energy Technology Laboratory, 3610 Collins Ferry Road, P.O.Box. 880 Morgantown, WV 26507, USA

${ }^{c}$ Department of Chemical Engineering, West Virginia University, Morgantown, WV 26506, USA

${ }^{d}$ AECOM/GES, Morgantown, WV 26507, USA

* Corresponding Author.

E-mail address: ed.sabolsky@mail.wvu.edu (E. M. Sabolsky).

\section{Abstract}

A bio-inspired surfactant was utilized to assist in the efficient impregnation of a nano- $\mathrm{CeO}_{2}$ catalyst throughout both porous Solid Oxide Fuel Cells (SOFC's) electrodes simultaneously. The process included the initial modification of electrode pore walls with a polydopamine film. The cell was then submersed into a cerium salt solution. The amount of nano- $\mathrm{CeO}_{2}$ deposited per impregnation step increased by 3.5 times by utilizing this two-step protocol in comparison to a conventional drip impregnation method. The impregnated cells exhibited a $20 \%$ higher power density than a baseline cell without the nano-catalyst at $750^{\circ} \mathrm{C}$ (using humid $\mathrm{H}_{2}$ fuel).

1

(C) 2015. This manuscript version is made available under the Elsevier user license http://www.elsevier.com/open-access/userlicense/1.0/ 
Keywords: SOFC, electrodes, nanomaterial, polydopamine, bio-inspired

\section{Introduction}

The introduction of oxide nano-catalysts into the electrode microstructures of Solid Oxide Fuel Cells (SOFC) through solution or suspension impregnation was demonstrated as a promising method to increase power performance of the fuel cells [1]. The various aspects of fuel and oxidant adsorption, and charge transfer kinetics, can be distinctly engineered by incorporating low volume fractions of nano-catalyst into the electrodes, and this can even be accomplished after the final sintering process for the SOFC membrane-electrode assembly (MEA) is completed. One attractive aspect of this method is that the performance of the SOFCs may be increased without any extensive alterations to the anode or cathode microstructure after initial cell fabrication. Typical nano-catalyst impregnated compositions used for SOFC electrodes have included doped- $\mathrm{CeO}_{2}, \mathrm{Cu}, \mathrm{Co}, \mathrm{Pt}$, and $\mathrm{Ni}$, [2] [3] [4] [5] [6] for the anode, and $\mathrm{Pd}$, doped- $\mathrm{CeO}_{2}$, ( $\mathrm{La}, \mathrm{Sr}) \mathrm{MnO}_{3}$ and ( $\left.\mathrm{La}, \mathrm{Sr}\right) \mathrm{CoO}_{3}$ [7] [8] [9] [10] for the cathode. Most papers in literature describe one major processing restriction for wet impregnation strategies; the process usually requires multiple impregnation and drying steps in order to achieve the desired nano-catalyst loading and to insure the proper increase in performance [11]. Multiple steps are required since preferential drying at the surface of the porous structure results in precipitate segregation and agglomeration, eliminating the ability to further incorporate more salt solution deeper into the microstructure.

To control the dispersion and wetting of porous structures with metal salt solutions, various additives such as Triton X-100 as a surfactant [12], glycol and citric acid as complexing agents 
[9] [12], and urea as a precipitation agent [13] were also introduced. The surfactants utilized for these works were specifically associated with the composition of the substrate and/or nanocatalyst; therefore, the surfactant system needed to be re-engineered for any change in the SOFC electrode or nano-catalyst composition. One potential solution to this issue is to use a versatile substrate modifying surfactant, such as poly-dopamine (PDA). PDA is a bio-chemical that is commonly found in nature, for example in mussel foot protein, where the molecule was shown to adsorb or react with various organic and inorganic materials [14]. Recent research showed that the deposition of nano-scale, two-dimensional films of metals, oxides, and polymers onto planar substrates with various chemistries can be achieved by surface modification of those surfaces with PDA. Hence, the prime advantage for using PDA as a surfactant is the ability to grow a thin film that allows for distinct control of the nucleation and growth rate of a broad spectrum of compositions through the simple tuning of the PDA solution concentration and immersion time [15].

The objective of this work was to investigate a facile dip-coating process for SOFC membranes to incorporate a controlled amount of nano-catalyst into both porous electrodes (anode and the cathode). For this process, the PDA surfactant was incorporated into the porous electrode structure through the first dip-coating procedure to control the heterogeneous nucleation mechanism (bio-coating) for nano-catalyst deposition. The second step included the dip-coating of the SOFC membrane to deposit the designated nano-catalyst at a specified rate and thickness. In this study, ceria $\left(\mathrm{CeO}_{2}\right)$ was used as the baseline catalyst composition to demonstrate the process. Finally, "off-the-shelf" SOFCs were utilized to demonstrate the applicability of the process to commercial cells, where the electrode microstructures did not need to be further 
modified in order to increase process efficiency, which is typically required for nanoinfiltration/impregnation methods.

\section{Experimental:}

Anode-supported button SOFCs (ASC-2.7, NexTech Materials, Ltd.) were used for this study. These cells were $27 \mathrm{~mm}$ in diameter and consist of a $240 \mu \mathrm{m}$ thick NiO/yttrium-stabilized zirconia (YSZ) anode, a dense $8 \mu \mathrm{m}$ thick YSZ electrolyte (27 $\mathrm{mm}$ in diameter), and a $(\mathrm{La}, \mathrm{Sr}) \mathrm{MnO}_{3}(\mathrm{LSM}) / \mathrm{LSM}-\mathrm{GDC}$ cathode, which was $12.5 \mathrm{~mm}$ in diameter and $50 \mu \mathrm{m}$ thick.

The modification of the electrodes was initially completed by incorporating the PDA into the porous electrode microstructures through a basic dip-coating (DC) process. The PDA solution was prepared by dissolving $1 \mathrm{mg} / \mathrm{ml}$ dopamine hydrochloride (99\%, Alfa-Aesar) into a $0.05 \mathrm{M}$ TRIS (tris(hydroxymethyl) aminomethane, 99\%, Alfa-Aesar) and 1:1 vol \% ethanol-water mixture at $\mathrm{pH}$ 8.5. The TRIS buffer stabilized the $\mathrm{pH}$ during the polymerization reaction [14]. Polymerization was confirmed visually by the transition of solution color from transparent to brown. Two PDA assisted dip-coating techniques were used in these experiments: 1) ex-situ polymerization (ex-situ DC PDA), in which the bio-coating solution was polymerized in a separate beaker before submersion of the SOFC membrane into the solution; and 2) in-situ polymerization (in-situ DC PDA), in which the bio-coating solution polymerization reaction was initiated after the SOFC was submerged into the solution. For the $e x$-situ polymerization process, a Nalgene ${ }^{\circledR}$ polyethersulfone $0.2 \mu \mathrm{m}$ syringe filter (Thermo Scientific) was used to filter the polymerized bio-coating solution to eliminate micron-sized PDA aggregates from the solution. 
These aggregates could potentially block pores and restrict the infiltration of the salt solution during the second step of the process.

The PDA bio-coating step was applied to both electrodes simultaneously by submerging the entire SOFC into a beaker containing the PDA solution. The beaker was placed within a vacuum chamber under a $30 \mathrm{~mm} \mathrm{Hg}$ vacuum for $5 \mathrm{~min}$. The beaker was removed from the vacuum chamber and transferred to a rocker table for $3 \mathrm{~h}$ in ambient conditions. The cell was then rinsed two times with a $50 \%$ ethanol-water mixture before immersing into the cerium solution. The cerium solution had a concentration of $0.4 \mathrm{M}$ within a 1:1 vol \% water-ethanol solvent, and cerium (III) nitrate hexahydrate (REacton ${ }^{\circledR}, 99.5 \%$, Alfa Aesar) was used as the salt to form the solution. The SOFCs remained submerged within the cerium solution on the rocking table for a $24 \mathrm{~h}$ period before removal. The surfaces of both electrodes were rinsed with a 1:1 vol \% waterethanol solution, and permitted to dry in ambient conditions. After drying, all impregnated cells were fired to $750^{\circ} \mathrm{C}$ to obtain pure ceria nanoparticles. The impregnated cells were weighed before and after firing to measure the degree of nano-catalyst incorporation.

In order to compare the effectiveness of the bio-coating procedures, the cells were dipped within the cerium solution for $24 \mathrm{~h}$, without pretreatment of the PDA surfactant. One SOFC sample was also impregnated using the conventional "dripping method", which is the conventional method demonstrated throughout literature. The experiment included dripping $1 \mathrm{ml}$ of $0.4 \mathrm{M}$ cerium (III) nitrate solution from the $1: 1 \mathrm{vol} \%$ ethanol-water mixture onto the anode side. The solution was dripped onto the top surface of the anode using a $3 \mathrm{ml}$ plastic pipette, before placing the cell under $30 \mathrm{~mm} \mathrm{Hg}$ vacuum. It should be noted that only the anode was impregnated with the 
cerium nano-catalyst for this baseline experiment. The sample was then dried in a vacuum oven at $50^{\circ} \mathrm{C}$. Fuel cell testing (current-voltage-power and impedance spectroscopy measurements) was performed at $750^{\circ} \mathrm{C}$ with humid $\mathrm{H}_{2}$ fuel, using the same procedure described in a previous paper [16].

\section{Results and Discussion}

The one-step conventional dripping method deposited approximately $0.4 \mathrm{mg}\left(0.33 \mathrm{mg} / \mathrm{cm}^{2}\right)$ $\mathrm{CeO}_{2}$. The dip-coated cell without PDA treatment gained $0.5 \mathrm{mg}$ of nano-catalyst within the electrodes. Note that the dip-coating method (using no PDA) was slightly more effective than the dripping method. The ex-situ polymerized PDA-assisted the dip-coating deposition by depositing $\sim 1.1 \mathrm{mg}$ of $\mathrm{CeO}_{2}$ nano-catalyst in a single step. The in-situ polymerized PDA-assisted dipcoating protocol deposited $1.4 \mathrm{mg}$ of nano-catalyst in a single step. These results show that the addition of the bio-coating pretreatment allowed for a 3.5 times increase in the catalyst deposition amount in a single step over the conventional dripping method.

Figure 1(a-d) are SEM cross-sectional images of the in-situ DC PDA dip-coated cell after testing for over $300 \mathrm{~h}$. The SEM micrograph shows the ceria nano-particles located within the bulk thickness and near the active layer of both the anode and cathode microstructure. The level of nano-catalyst deposition into the active anode layer was shown to be lower due the thickness ( 240 micron thick) and density of un-reduced anode supports structures. This result highlights the limitation of infiltrating commercial anode-supported cells, where the unreduced microstructure usually possesses $<30$ vol\% porosity, and hence restricts efficient impregnation to the active layer. The deposition within the cathode is extensive, where the single catalyst 
impregnation step resulted in a filled cathode porosity. The enhanced nano- $\mathrm{CeO}_{2}$ deposition on the cathode side can be attributed to the high porosity level (35-45\%) and relative thinness $(\sim 50$ $\mu \mathrm{m})$ of the cathode layer. The particle size of the infiltrated nano-catalyst was approximately 20$50 \mathrm{~nm}$ after $300 \mathrm{~h}$ testing.

The SOFCs that utilized the two-step bio-coating process (where only one thermal treatment was used) were characterized using both current-voltage-power (I-V-P) measurements and electrochemical impedance spectroscopy (EIS). The SOFCs were tested under constant current conditions $\left(0.33 \mathrm{~A} / \mathrm{cm}^{2}\right)$ using humid $\mathrm{H}_{2}$ fuel at $750^{\circ} \mathrm{C}$ for approximately $300 \mathrm{~h}$. Again, the nanoceria was incorporated into both the anode and cathode microstructure simultaneously. Figure 2 displays the current-voltage-power (I-V-P) curves for the SOFCs pre-treated with PDA (both through an in-situ and ex-situ polymerization process) and a baseline SOFC with no nanocatalyst incorporation. The I-V-P curves were taken before constant current loading at $0 \mathrm{~h}$, and after $300 \mathrm{~h}$ of constant current loading. The data indicated an appreciable initial enhancement in power density by $20.7 \%$ and $17.9 \%$ for the ex-situ DC PDA and in-situ DC PDA samples, respectively. After approximately $300 \mathrm{~h}$ of fuel cell testing, the power density of the impregnated cells was $1.5 \%$ and $5.8 \%$ higher than the baseline performance, respectively. This depicts a higher gap in performance change for the ex-situ polymerized PDA dip-coated cells, which exhibited an $11.5 \%$ degradation. In the in-situ polymerized PDA, the degradation was around $5.6 \%$. 
The degradation in power density was due to the sintering of the impregnated nano-catalyst over time at the operating temperature. In literature, it has been demonstrated that metallic $(\mathrm{Ni}, \mathrm{Pd}, \mathrm{Pt})$ nanoparticles (with low thermal stability) and non-metallic (NiO, SDC, $\mathrm{CeO}_{2}, \mathrm{GDC}, \mathrm{LSM}$ ) nanoparticles tend to coarsen over time leading to reduced surface area, activity, and triple-phase boundary area which all affects the performance of the cell [17] [18] [19] [20] [21]. Our AFM study on the PDA-assisted dip-coated protocol on YSZ single crystals, confirmed this phenomenon by showing that the initial particle size of cerium oxide particles was $2-3 \mathrm{~nm}$ (results not shown). As noted above after testing in $\mathrm{H}_{2}$ for $300 \mathrm{~h}$, the particle size of the catalyst increased to 20 to $50 \mathrm{~nm}$. In this way, an in-situ bio-coating process encouraged better penetration of the PDA to the electrode active zone before polymerization. This resulted in better homogeneity throughout the porous 3-D structure and hence improving the catalyst island distribution.

EIS Nyquist plots, shown in Figure 3.a, display a total electrode polarization resistance $\left(\mathrm{R}_{\mathrm{p}}\right)$ of $0.31 \mathrm{ohm} \cdot \mathrm{cm}^{2}$ for the $e x$-situ DC PDA cell and $0.32 \mathrm{ohm} \cdot \mathrm{cm}^{2}$ for the $i n$-situ DC PDA cell. The $\mathrm{R}_{\mathrm{p}}$ for the baseline cell was measured as $0.41 \mathrm{ohm} \cdot \mathrm{cm}^{2}$. These values correspond to a $23.4 \%$ and $21.7 \%$ decrease in $\mathrm{R}_{\mathrm{p}}$ for the ex-situ and in-situ DC PDA samples, respectively. However, as the time proceeded to $300 \mathrm{~h}$, the $\mathrm{R}_{\mathrm{p}}$ of the cells was observed to increase. Bode plots depicted in Fig. 3.b were generated to understand the electrochemical mechanisms and associated frequency regions. It has been established that region 1 is associated with the the anode charge transfer reaction [10] [22]; region 2 is associated with the cathode polarization [10] [23]; and region 3 is related to gas diffusion limitations [10] [24]. As shown in Figure 3.b, the infiltrated cells displayed a significant decrease in region 1 and a slight decrease in regions 2 and 3. This means 
that the nano- $\mathrm{CeO}_{2}$ activated both the anode and cathode sides due to the dual impregnation. Moreover, an increase in resistance over time in regions 1 and 2 was observed, suggesting that the anode and cathode showed deactivation due to the catalyst sintering/growth. The growth of the catalyst particles, and the backbone structure, may be responsible for the decrease in region 3 , which indicates a relaxation of the cathode gas path through the active area.

\section{Conclusion}

In this study, polydopamine (PDA), a bio-inspired surfactant, was coated throughout the porosity of both SOFC electrodes (cathode and anode) in order to enhance and control the deposition of nano- $\mathrm{CeO}_{2}$ catalyst throughout the microstructure. The entire impregnation process consisted of two dip-coating steps. The process included the initial submersion of the entire SOFC into a PDA solution, followed by the dip-coating of the cell into a cerium salt solution. The process was completed by a drying and high-temperature thermal treatment. The simple dip-coating protocol showed enhanced penetration and distribution of the nano-catalyst in both electrodes. The work demonstrated the process using existing commercial cell architectures (with the typical low porosity in the unreduced anode state), where most impregnation studies require the redesign of the SOFC electrode microstructure in order to facilitate liquid penetration. As indicated, ceria was used to demonstrate the efficacy of the protocol, but the method permits the deposition of other catalyst compositions targeted for singular or dual electrode performance enhancement.

Although the use of both the PDA surfactant and the dip-coating process showed an overall enhanced deposition efficiency, the work also highlighted the need for better control of the deposition rate when the electrodes display a different level porosity (such as the anode and cathode in this work) for dual impregnation. Although dual impregnation was focused upon in 
this work, a single electrode can also be infiltrated with promising catalyst(s) by masking the other electrode. In the end, the simple and efficient process resulted in a drastic decrease in the polarization resistances of both electrodes. Unfortunately, as in most nano-catalyst impregnation studies described in literature (and also shown in this work), nano-catalyst sintering and grain growth decreased the enhanced performance achieved through the impregnation process, and further work is needed to stabilize the microstructure for sustained performance enhancement.

\section{References}

[1] Jiang, SJ. A review of wet impregnation - An alternative method for the fabrication of high performance and nano-structured electrodes of solid oxide fuel cells. Materials Science and Engineering 2010;418:199-210.

[2] Sholklapper TZ, Jacobson CP, Visco SJ, De Jonghe LC. Synthesis of Dispersed and Contiguous Nanoparticles in Solid Oxide Fuel Cell Electrodes. Fuel Cells 2008;8:303-312.

[3] Kurokawa H, Sholklapper TZ, Jacobson CP, De Jonghe LC, Visco, SJ. Ceria Nanocoating for Sulfur Tolerant Ni-Based Anodes of Solid Oxide Fuel Cells. Electrochemical and Solid-State Letters 2007;10:135-8.

[4] Lee S-I, Vohs JM, Gorte RJ. A study of SOFC anodes based on $\mathrm{Cu}-\mathrm{Ni}$ and $\mathrm{Cu}-\mathrm{Co}$ bimetallics in CeO2-YSZ. Journal of The Electrochemical Society 2004;151:1319-23.

[5] McIntosh S, Vohs JM, Gorte RJ. Effect of precious-metal dopants on SOFC anodes for direct utilization of hydrocarbons. Electrochemical and Solid-State Letters 2003;6:240-3.

[6] Qiao J, Sun K, Zhang N, Sun B, Kong J, Zhou D. Ni/YSZ and Ni-CeO2/YSZ anodes prepared by impregnation for solid oxide fuel cells. Journal of Power Sources 2007;169:253-8. 
[7] Liang F, Chen J, Jiang SP, Chi B, Pu J, Jian L. Development of nanostructured palladium promoted (La,Sr)MnO3- based cathodes for intermediate-temperature SOFCs. Electrochemical and Solid-State Letters 2008;11:213-6.

[8] Jiang SP, Wang W. Fabrication and performance of GDC impregnated (La,Sr)MnO3 cathodes for intermediate. Journal of The Electrochemical Society 2005:152:1398-408.

[9] Jiang Z, Lei Z, Ding B, Xia C, Zhao F, Chen F: Electrochemical characteristics of solid oxide fuel cell cathodes prepared by infiltrating $(\mathrm{La}, \mathrm{Sr}) \mathrm{MnO} 3$ nanoparticles into yttria-stabilized bismuth oxide backbones. International Journal of Hydrogen Energy 2010;35:8322-30.

[10] Lee S, Miller N, Gerdes K. Long-term stability of SOFC composite cathode activated by electrocatalyst infiltration. Journal of Electrochemical Society 2012;159:301-8.

[11] Jiang, SP. Nanoscale and nano-structured electrodes of solid oxide fuel cells by infiltration: Advances and challenges. International Journal of Hydrogen Energy 2012;37:449-70.

[12] Nicholas JD, Barnett, SA. Measurements and podeling of $\mathrm{Sm} 0.5 \mathrm{Sr} 0.5 \mathrm{CoO}{ }^{-} \mathrm{x}-$ Ce0.9Gd0.1O1.95 SOFC cathodes produced using infiltrate solution additives. Journal of The Electrochemical Society 2010;157:536-41.

[13] Shishido T, Yamamoto Y, Morioka H, Takaki K, Takehira K. Active $\mathrm{Cu} / \mathrm{ZnO}$ and $\mathrm{Cu} / \mathrm{ZnO} / \mathrm{A} 12 \mathrm{O} 3$ catalysts prepared by homogeneous precipitation method in steam reforming of methanol. Applied Catalysis A: General 2004; 263:249-53.

[14] Lee H, Dellatore SM, Miller WM, Messersmith PB. Mussel-inspired surface chemistry for multifunctional coatings. Science 2007;318:426-30.

[15] Liu Y, Ai K, Lu L. Polydopamine and its derivative materials: synthesis and promising applications in energy, environmental, and biomedical fields. Chemical Reviews 2014;114: 5057-115. 
[16] Gandavarapu SR, Sabolsky K, Gerdes, K, Sabolsky EM. Direct foamed and nano-catalyst impregnated solid-oxide fuel cell (SOFC) cathodes. Materials Letters 2013;95:131-4.

[17] Tucker MC, Lau GY, Jacobson CP, DeJonghe LC, Visco SJ. Stability and robustness of metal-supported SOFCs. Journal of Power Sources 2008;175:447-51.

[18] Stevenson, JW. et al. Development of lanthanum ferrite SOFC cathodes. Journal of Power Sources 2003;113:1-10.

[19] Okawa Y, Matsumoto T, Doi T, Hirata Y. Thermal stability of nanometer-sized NiO and Sm-doped ceria powders. Journal of Materials Research 2002;17:2266-74.

[20] Rupp JLM, Infortuna A, Gauckler, LJ. Microstrain and self-limited grain growth in nanocrystalline ceria ceramics. Acta Materialia 2006;54:1721-30.

[21] Shah M, Hughes G, Voorhees PW, Barnett SA. Stability and performance of LSCFinfiltrated SOFC cathodes: effect of nano-particle coarsening. ECS Transactions 2011;35:204553.

[22] Leonide A, Sonn V, Weber A, Ivers-Tiffée E. Evaluation and modeling of the cell resistance in anode-supported solid oxide fuel cells. Journal of Electrochemical Society 2008;155:36-41.

[23] Chen XJ, Khor KA, Chan SH. Identification of O2 reduction at yttria stabilized zirconia doped lanthanum manganite interface. Journal of Power Sources 2003;123:17-25.

[24] Endler C, Leonide A, Weber A, Tietz F, Ivers-Tiffée E. Time-Dependent electrode performance changes in intermediate temperature solid oxide fuel cells. Journal of The Electrochemical Society 2010;157:292-8.

\section{Acknowledgements}

As part of the Department of Energy (DOE) National Energy Technology Laboratory's Regional University Alliance (NETL-RUA), a collaborative initiative of the NETL, this technical effort 
was performed under the contract DE-FE0004000. The authors would like to acknowledge James Poston at NETL-Morgantown for his assistance in SEM/EDS characterization. The WVU Shared Research Facilities are also acknowledged for their assistance in materials characterization.

\section{Figure Captions:}

Figure 1: Cross section SEM images of in-situ DC PDA dip coated cell, which were taken from the anode a) middle layer, b) active layer, and cathode c) middle layer, d) active layer of the anode-supported cell after testing at $750^{\circ} \mathrm{C}$ for 300 hours in hydrogen.

Figure 2: I-V-P curves of baseline and impregnated SOFCs using the in-situ and ex-situ polymerized PDA surfactant before nano-ceria impregnation.

Figure 3: a) Nyquist and b) Bode plots of the baseline and bio-coating assisted dip-coat infiltrated cells under $0.4 \mathrm{~A}$ at $750{ }^{\circ} \mathrm{C}$. 

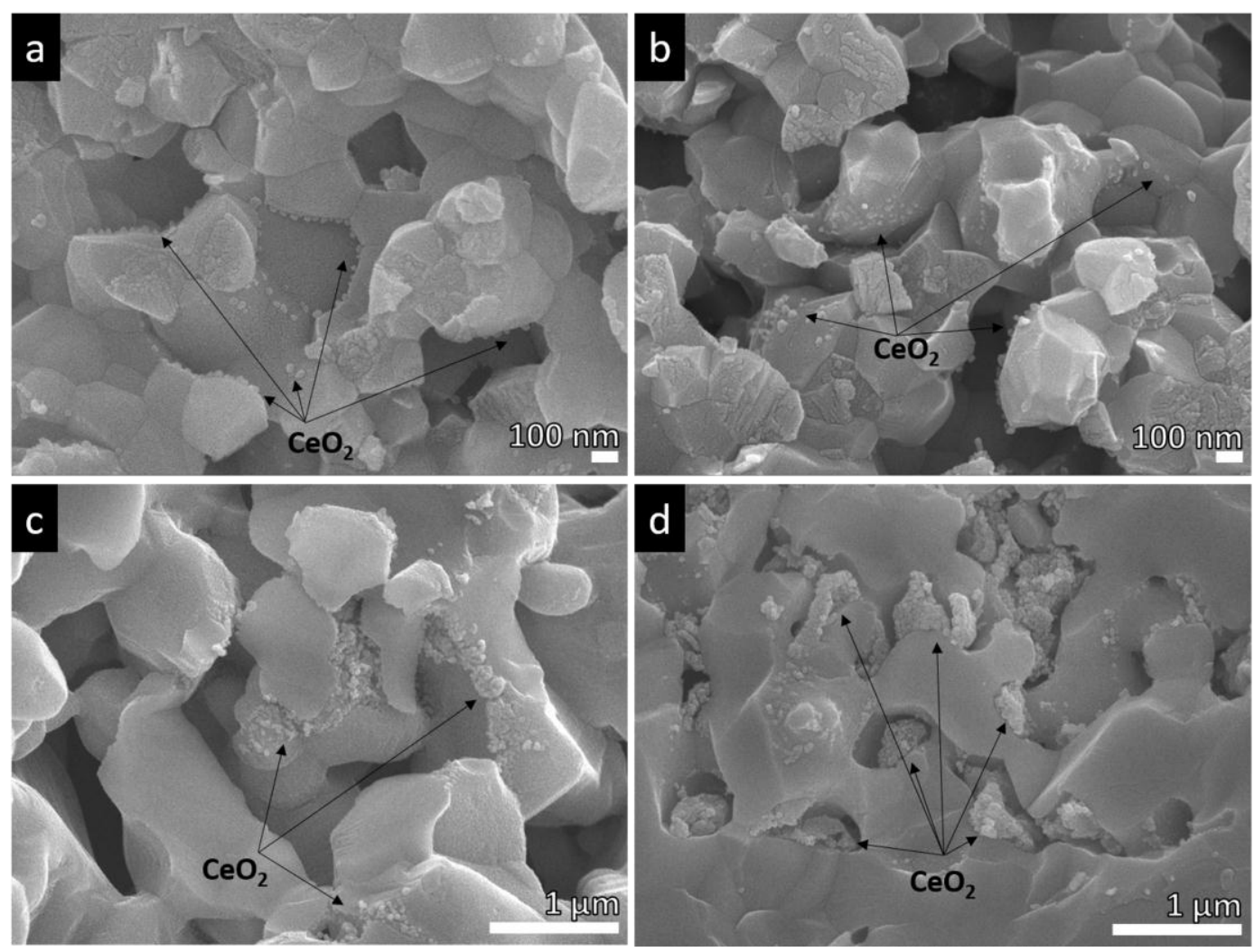

Figure 1. Cross section SEM images of in-situ DC PDA dip coated cell, which were taken from the anode a) middle layer, b) active layer, and cathode c) middle layer, d) active layer of the anode-supported cell after testing at $750^{\circ} \mathrm{C}$ for 300 hours in hydrogen. 


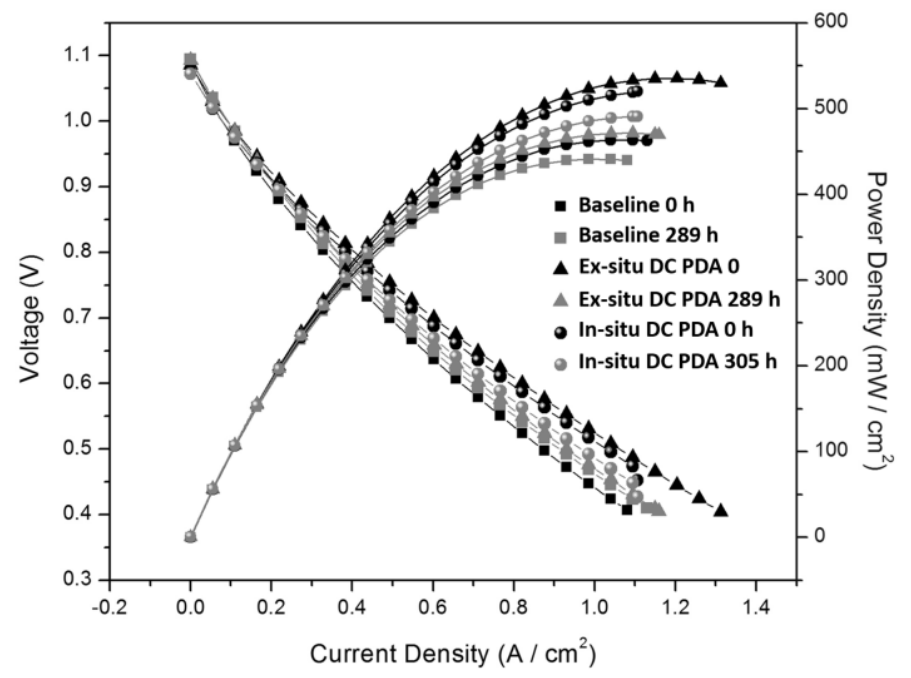

Figure 2. I-V-P curves of baseline and impregnated SOFCs using the in-situ and ex-situ polymerized PDA surfactant before nano-ceria impregnation. 


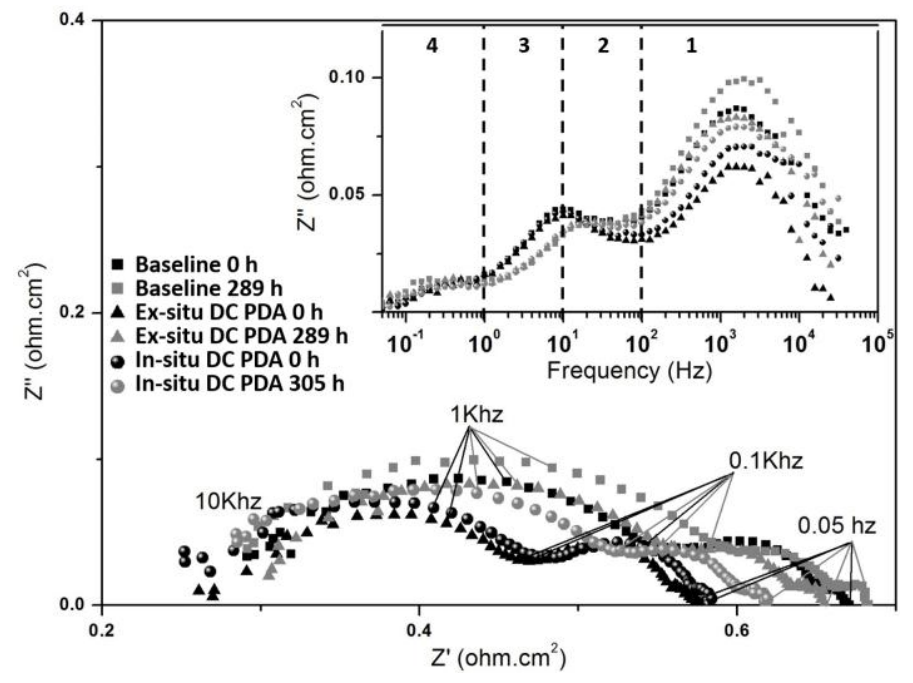

Figure 3. a) Nyquist and b) Bode plots of the baseline and bio-coating assisted dip-coat infiltrated cells under $0.4 \mathrm{~A}$ at $750{ }^{\circ} \mathrm{C}$. 